\title{
Flow properties of finely dispersed binder
}

\author{
Olga Bazhenova ${ }^{1}$, Sophia Bazhenova ${ }^{1 *}$, Marat Bazhenov ${ }^{1}$, Saak Ambaryan ${ }^{1}$, and Mikhail \\ Gleyzer $^{1}$ \\ ${ }^{1}$ Moscow State University of Civil Engineering, Yaroslavskoe shosse, 26, Moscow, 129337, Russia
}

\begin{abstract}
This article contains information about strengthening the underground parts of buildings and restoration of their bearing capacity, along with solutions of urea-formaldehyde resin and solutions based on sodium silicate (which have a number of significant drawbacks, such as short-lived strengthening, low strength of reinforced soil (0.1-0.5 MPa), brittle destruction under dynamic loads, environmental pollution), using impregnation compositions based on fine mineral binders. This compositions, with the name «Mikrodur», are obtained on the basis of air separation of Portland cement CEM I 52.5 (PC D0 M600) and fine-divided blast furnace slag. The method of preparation of suspension on the basis of finely dispersed binder is considered. The main characteristics determining the finely dispersed binder suspension, such as viscosity and stability of the injectable suspension (sedimentation), are established. It is proved that the indexes of viscosity and stability of solutions depend on the method of their preparation, water/binding ratio and chemical admixtures. A variety of finely dispersed binders grades on mineral composition allows providing ground, stone and concrete structures of underground constructions stabilization taking into account various requirements: strength enhancement and anti-filtration properties of the strengthened masses, their resistance to various aggressive influences, the possibility of hardening in conditions of negative temperature, acceleration of a strength enhancement.
\end{abstract}

\section{Introduction}

In many industries, the filling of pores and capillaries of materials with special compositions to give them special properties is achieved by impregnation. At the moment, there are several ways of impregnation of building products of inorganic origin, which have a system of connected closed and open capillaries. A systematic search for new ways of anti-filtration protection shows that the existing methods for one reason or another do not fully meet the requirements for them. Physical and chemical interaction between the solid capillary-porous body and the impregnating agent is that the impregnant has an increased adhesion to the monolith`s surface due to the partial chemical bond with the minerals of the capillary-porous construction product. P.A. Rehbinder and I.A. Ryb'ev [1,2] in their works consider the processes and phenomena from the standpoint of physicochemical mechanics, for example, the sorption occurring in solids in the impregnation of their various fluids. Sorption is a physico-

\footnotetext{
* Corresponding author: sofia.bazhenova@gmail.com
} 
chemical process as a result of which the capillary-porous body absorbs gases, steam-air medium, liquids or any other substances that are in a light-moving or gaseous state. According to I.A. Ryb'ev [2], penetration by diffusion of water, which occurs due to sorption, is observed even in such substances as bitumen, paraffin, wax, stearin, naphthalene, etc. There are surface modification of capillary-porous products, where a slight penetration of the composition into the body of the material is required, and volumetric - when the impregnation of the entire product is necessary.

In all cases of use of impregnation low penetrability of impregnating compounds is noted. Attempts have been made to intensify the process through the use of various auxiliary procedures. But in these cases, no positive results were achieved. Currently, the increase in the speed and depth of penetration of the impregnating composition into the porous-capillary material is carried out mainly in the following areas: the use of vacuum and pressure in the process of impregnation, the use of elevated temperature, the selection of low-viscosity impregnating compounds. It should be emphasized that the most effective is the method of impregnation of capillary-porous materials by vacuum injection method [3].

One of the main factors affecting the infiltration rate is the viscosity of the impregnating compound [4]. As the temperature increases, the viscosity of the liquid significantly decreases and the infiltration rate increases.

For stabilization and compaction of soils, which are also capillary-porous bodies, injectable solutions, which are based on mineral and polymer binders, could be used. Preference is given to mineral-based solutions, as they provide higher strength properties of soil stabilization and are environmentally friendly materials. However, with traditional methods of injection, the use of mineral-based solutions is limited by the characteristics of the soil - the filtration coefficient and the dispersion of the material used for the preparation of injectable solutions. Solutions based on silicates and resins should be used to stabilize low-permeable (sandy, sabulous) soils. Experience in compaction and improvement of water resistance of soils, represented mainly by fine-grained sands and sandy loams, in the transport tunnels of the Moscow and Nizhniy Novgorod subway system showed that solutions of urea-formaldehyde resin and solutions based on sodium silicate were mainly used for the injection of soils. However, silicate gels and solutions of urea-formaldehyde resins have a number of significant drawbacks: low strength of reinforced soil (0.1-0.5 MPa), destruction under dynamic loads, and in addition their use leads to environmental pollution [5, 6].

The urgent task is the need to replace the urea-formaldehyde resins resin with a similar material in terms of technological parameters, but environmentally friendly and providing high strength characteristics of soils [7, 8, 9]. For the injection of loose rocks with finely dispersed binders "Mikrodur", which are obtained by air separation of Portland cement CEM I 52.5 (PC D0 M600) and fine-divided blast furnace slag could be more effective. These binders could be used for the injection of soil, as well as structures of foundations, hydraulic and underground structures.

\section{Methods and Materials}

To provide experimental part, finely dispersed binder "Mikrodur" (FDB) with three grades: R-U, R-X, R-F were used as test materials for sealing and ground stabilization. Grade "R" contains a large number of blast furnace slag along with Portland clinker. FDB has high resistance to sulfate corrosion. A variety of grades of FDB on mineral composition allows providing soil stabilization, strengthening of underground structures taking into account various requirements: strength enhancement and anti-filtration properties of the strengthened masses, their resistance to various aggressive influences, the possibility of hardening in the conditions of negative temperature, acceleration of a strength enhancement. Table 1 and 2 
show the diameters of FDB particles of different grades of dispersion with a weight percentage of 85 and their grain size.

Table 1. FDB grades by dispersion

\begin{tabular}{|c|c|}
\hline FDB grades by dispersion & $\mathrm{d}_{85}, \mu \mathrm{m}$ \\
\hline R-X & 4,5 \\
\hline R-U & 7,0 \\
\hline R-F & 11,0 \\
\hline
\end{tabular}

Table 2. FDB grain size for different grades

\begin{tabular}{|c|c|c|c|c|c|c|c|c|}
\hline \multirow{2}{*}{ Grade } & \multicolumn{6}{|c|}{ Number of particles $(\%)$ with diameter $(\mu \mathrm{m})$} & \multirow{2}{*}{$\begin{array}{l}\text { Specific surface } \\
\text { area, } \mathrm{m}^{2} / \mathrm{kg}\end{array}$} & \multirow{2}{*}{$\begin{array}{l}\text { Water de- } \\
\text { mand, \% }\end{array}$} \\
\hline & $<2$ & $<4$ & $<6$ & $<9,5$ & $<16$ & $<24$ & & \\
\hline $\mathrm{R}-\mathrm{F}$ & 19 & 45 & 60 & 80 & 95 & - & 1200 & 39,0 \\
\hline $\mathrm{R}-\mathrm{U}$ & 25 & 55 & 78 & 95 & - & - & 1600 & 47,0 \\
\hline $\mathrm{R}-\mathrm{X}$ & 45 & 80 & 95 & - & - & - & 2200 & 61 \\
\hline
\end{tabular}

In the presence of complex injection conditions or with a W/B ratio of suspension with less than 4.0, it is recommended to use plasticizers (S-3, surfactants, etc.) in an amount of 1$3 \%$ of the binder weight. Superplasticizer S-3 was used in the work.

Tap water is used to gauge the binder. It must meet the requirements of GOST 237322011 «Water for concrete and mortars. Specifications». A suspension is prepared for impregnation of capillary-porous materials. The mixing plant shall provide the speed of rotation of the activator not less than $2800 \mathrm{rpm}$. The engine power of the mixing plant shall be not less than $1 \mathrm{~kW}$ for each $20 \mathrm{~L}$ of the prepared suspension. Mixing time is 5 minutes.

The main characteristics that determine the suspension of FDB are:

- viscosity - internal friction, the property of fluid bodies (liquids and gases) to resist the movement of one part relative to the other;

- sedimentation is the process by which suspended solids are separated from water by gravity and deposited at the bottom of a container or tank.

The viscosity is determined by the expiration time in seconds of $1 \mathrm{dm}^{3}$ suspension from the Marsh funnel. In addition to the Marsh funnel, measuring viscosity requires a measuring cup and a stopwatch. Deviation of the actual time of expiration of $1 \mathrm{dm}^{3}(\mathrm{~L})$ of the suspension from the Marsh funnel from the standard (table 3) within \pm 1 second is allowed.

Table 3. Standart time of efflux of suspension from the Marsh funnel for FDB with different water/binder ratio $(\mathrm{W} / \mathrm{B})$

\begin{tabular}{|c|c|c|c|c|c|}
\hline \multirow{2}{*}{ FDB grade } & \multicolumn{5}{|c|}{ The time of efflux of a suspension at W/B, s } \\
\cline { 2 - 6 } & 1,0 & 2,0 & 3,0 & 4,0 & 5,0 \\
\hline R-X & 36 & 29 & 28 & 28 & 28 \\
\hline R-U & 37 & 29 & 28 & 28 & 28 \\
\hline R-F & 38 & 29 & 29 & 29 & 28 \\
\hline
\end{tabular}

Sedimentation is determined on a working suspension in a graduated cylinder with a capacity of about $500 \mathrm{ml}$. Experiments are carried out at a temperature of $20 \pm 1^{\circ} \mathrm{C}$. Water for mixing and FDB must have the same temperature. To observe the progress of the process of the water segregation, depending on the time elapsed from the beginning of the experiment, 
the volume of the settled cement paste is noted every 15 minutes for 1 hour and every 30 minutes with further observations. For the beginning of the experiment at the same time take the moment of the first reference of the volume of the cement paste. When the last two counts are the same, further observations are stopped and the content of the cylinder is poured.

The period of complete water segregation is characterized by the time that has passed from the beginning of the experiment to the end of the water segregation process, that is, to the last count on the cylinder. Typically, the segregation of water from the binder should not exceed $10 \%$. The coefficient of water segregation (\%) on each period is calculated by the following formula:

$$
K_{w}=\left(V_{1}-V_{2}\right) 100 / V_{1}
$$

$\mathrm{V}_{1}$ - the initial volume of the suspension, $\mathrm{cm}^{3}$

$\mathrm{V}_{2}$ - volume of the suspension which has settled for this period, $\mathrm{cm}^{3}$

$\left(\mathrm{V}_{1}-\mathrm{V}_{2}\right)$ - the volume of water segregated during this period, $\mathrm{cm}^{3}$

\section{Results and Discussion}

Effective soil stabilization depends on the water/binding ratio, which determines the viscosity and stability of the injectable suspension. Reducing the viscosity and increasing the stability of the suspension increases the guarantee of effective injection, i.e. increases the penetrating ability of the injection solution into the capillary-porous body. Indexes of viscosity and stability of solutions depend of the method of their preparation, water/binding ratio and chemical admixtures. In accordance with this, the main technical parameters of the injectable solution (viscosity, sedimentation) and their change in time depending on the W/B ratio and additives of the plasticizer were determined. The nature of the change in the viscosity of the solution depending on the $\mathrm{W} / \mathrm{B}$ showed that for the values of $\mathrm{W} / \mathrm{B}=3.0$ and more, the viscosity of the suspension varies slightly (table 4 ) and practically equal to the viscosity of water. The viscosity of the water determined by the Marsh funnel at $20^{\circ} \mathrm{C}$ is about $28 \mathrm{sec}$. For W/B values from 3.0 and below, the viscosity of the suspension increases significantly in proportion to the reduction of the $\mathrm{W} / \mathrm{B}$ ratio.

Table 4. Determination of time of efflux of the suspension from the Marsh funnel

\begin{tabular}{|c|c|c|c|c|c|}
\hline \multirow{2}{*}{ FDB grade } & \multicolumn{5}{|c|}{ The time of efflux of a suspension at W/B, s } \\
\cline { 2 - 6 } & 1,0 & 2,0 & 3,0 & 4,0 & 5,0 \\
\hline R-X & 35 & 30 & 29 & 28 & 28 \\
\hline R-U & 36 & 30 & 29 & 28 & 28 \\
\hline R-F & 37 & 30 & 29 & 29 & 28 \\
\hline
\end{tabular}

In order to reduce the viscosity of the suspension in its composition is allowed to use up to $3.0 \%$ superplasticizer S-3 (table 5), which reduces the time of efflux of a suspension, especially when $\mathrm{W} / \mathrm{B}=2.0$ or lower.

Table 5. Reducing the viscosity of FDB suspension by adding plasticizers

\begin{tabular}{|c|c|c|c|}
\hline \multirow{2}{*}{$\begin{array}{c}\text { Amount of plasticizer by } \\
\text { weight of binder, } \%\end{array}$} & \multicolumn{3}{|c|}{ Reducing the time of efflux of a suspension in different W/B, \% } \\
\cline { 2 - 4 } & 1,0 & 2,0 & 3,0 \\
\hline 1 & 3 & 2 & 0,5 \\
\hline 2 & 6 & 4 & 1 \\
\hline 3 & 10 & 7 & 2 \\
\hline
\end{tabular}


When adding the plasticizer to the suspension, its consistency remains unchanged even at $\mathrm{W} / \mathrm{B}=0.7$ for 1.5 hours and is almost equal to the consistency of water. The time of usability of the suspension for injection was determined as $60 \%$ of the time from the preparation time to the start of the suspension setting.

The stability of the suspension, which is characterized by sedimentation or water segregation, decreases with increasing the W/B ratio. When the injectable solution is treated with a plasticizer, the stability of the suspension increases, and its penetration into the capillary-porous structure of the materials increases. The addition of plasticizers provides a noticeable effect when using FDB suspensions with a W/B ratio of less than 4.0.

As can be seen from table 6, when using the plasticizer, the stability of the suspension increases. The quality of FDB suspension is normal if the sedimentation of the suspension with $\mathrm{W} / \mathrm{B}=2.0$ does not exceed $8.54 \%$ for 60 minutes after mixing at a temperature of $21^{\circ} \mathrm{C}$.

It is allowed to exceed the actual sludge of suspension for 60 minutes from the normative, but not more than $5 \%$.

Table 6. The influence of the plasticizer on the sedimentation of FDB

\begin{tabular}{|c|c|c|c|c|c|c|}
\hline \multirow{2}{*}{$\begin{array}{c}\text { Amount of plasti- } \\
\text { cizer by weight of } \\
\text { binder, \% }\end{array}$} & 15 min. & 30 min. & 45 min. & 60 min. & 90 min. & 120 min. \\
\cline { 2 - 7 } & 1,2 & 2,4 & 2,9 & 3,6 & 4,8 & 6 \\
\hline- & 0,8 & 1,9 & 2,4 & 3,0 & 4,1 & 4,7 \\
\hline 1 & 0,5 & 1,2 & 1,6 & 2,0 & 2,6 & 3,1 \\
\hline 2 & & & & & &
\end{tabular}

In addition, using the superplasticizer is effective for suspensions when we need to inject soils with reduced permeability (clay sands, dust sand, fissured rocky soils).

\section{Conclusions}

Analyzing the results of the tests, and summarizing the above, we can draw the following conclusions:

- injectable suspensions at $\mathrm{W} / \mathrm{B}=1-5$ have a low viscosity (from 28 - $36 \mathrm{~s}$ along the Marsh funnel), which is comparable to the viscosity of solutions based on urea-formaldehyde resins $(28-33 \mathrm{~s})$ and water $(28 \mathrm{~s})$;

- using to $3.0 \%$ of superplasticizer S-3 leads to reduction of time of efflux of a suspension, especially when $\mathrm{W} / \mathrm{B}=2.0$ or lower;

- when the injectable solution is treated with a plasticizer, the stability of the suspension increases and its penetration into the capillary-porous structure of the materials increases.

Finely dispersed binder allows providing soil stabilization, strengthening of underground structures taking into account various requirements: strength enhancement and anti-filtration properties of the strengthened masses, their resistance to various aggressive influences, the possibility of hardening in the conditions of negative temperature, acceleration of a strength enhancement.

\section{References}

1. P.A. Rehbinder, Fiz.-mech. Issl Proc Def. Tv Tel, 1 (USSR Academy of Sciences Publishing House, Moscow, 1947)

2. I.A.Rybev, Construction material science (Vyshaya shkola, Moscow, 2002)

3. Y.M. Bazhenov, Concrete polymers (Stroyizdat, Moscow, 1983) 
4. E.L. Gurevich, B.V. Gusev, U.K. Magdeev, K.G. Khabakhpashev, Prom. Stroit. Mat M. 6, 13 (1976)

5. V.A. Ashikhmen, Prim. Tsem. Rastv. Pov. Pronik 1, 19 (1992)

6. A.V. Abakumov, Sv. i Pr. Vys. Tsem. Tamp Rastv. (VTSR), 5, 21 (1997)

7. B.A. Rzhanitsyn, Chemical fixing of soils in construction (Stroyizdat, Moscow. 1986)

8. I.Y. Kharchenko, Tekhn. «INTRABAU-Mikrodur», 8, 24 (2003)

9. I.Y. Kharchenko, Tekhn. «INTRABAU-Mikrodur», 11, 18 (2003)

10. A.I. Panchenko, I.Y. Kharchenko, Os. Tonk Min. Viazh «Mikrodur» Sv. Tek i Per Isp., 10, 26 (2005) 